\begin{tabular}{c} 
Volume and Issues Obtainable at Center for Sustainability Research and Consultancy \\
Journal of Business and Social Review in Emerging Economies \\
ISSN: 2519-089X (E): 2519-0326 \\
Volume 6: No. 2,June 2020 \\
CSRᄃ \\
Journal homepage: www.publishing.globalcsrc.org/jbsee \\
\hline
\end{tabular}

\title{
Aquatic Exercise to Treat Pregnancy Related Issues in Pregnant Women: A Systematic Review
}

\author{
${ }^{1}$ Asif Ali, ${ }^{2}$ Muhammad Azam, ${ }^{3}$ Zargham ul Hassan Askry \\ ${ }^{1}$ Associate Professor, Department of Physical Education and Sports Sciences, Government College \\ University, Lahore. Corresponding author: Email: goraya128@ hotmail.com \\ ${ }^{2}$ Assistant Professor, Department of Physical Education, Government College University Lahore, \\ Pakistan,goraya78@gmail.com \\ ${ }^{3}$ M.sc student, Department of Physical Education, GC University Faisalabad, Pakistan.
}

\begin{tabular}{l} 
ARTICLE DETAILS \\
\hline History \\
Revised format: May 2020 \\
Available Online: June 2020
\end{tabular}

\section{Keywords}

Aquatic exercise, exercise in water, pregnancy, pregnant women, pregnancy related outcomes

\section{JEL Classification:}

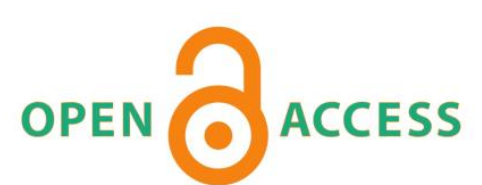

\section{ABSTRACT}

Background: Wide ranges of physiological changes occur as a result of pregnancy in women that, in certain cases, may cause variety of psychological and physical problems in pregnant women. Aquatic exercises believed to be safe for pregnant women and believed to foster positive effect on psychophysical health.

Purpose: This review sought to synthesize qualitatively the existing research evidences concerning association between aquatic exercises and psychophysical problems in pregnant women.

Methods: A 1989 records were yielded as result of conducting a systematic search in nine research data bases. After undergoing rigorous screening and assessment procedure of eligibility, and quality appraisal, a total of seventeen research articles were ultimately selected to include in this review.

Results: Out of seventeen admissible studies, ten studies found that aquatic exercises exerts positive impact to decreases variety of physical discomforts such as fatigue, pelvic pain, labor pain, and edema. The remaining seven studies presented beneficial effects of aquatic exercises for psychological factors such as body image, stress, depression, feelings, mood, distress, and anxiety in pregnant women.

Conclusion: This review found some evidence in support of the efficacy of aquatic exercises to reduce physical discomfort and improve psychological factors in pregnant women.

(C) 2020 The authors, under a Creative Commons Attribution-

NonCommercial 4.0

Corresponding author's email address: goraya128@hotmail.com

Recommended citation: Ali, A., Azam, M., Askry Z.U.H. (2020). Aquatic Exercise to Treat Pregnancy Related Issues in Pregnant Women: A Systematic Review. Journal of Business and Social Review in Emerging Economies, 6(2), 391-400

DOI: $10.26710 /$ jbsee.v6i2.1098 


\section{Introduction}

Women during pregnancy experience variety of mental and physical disorders. For example, psychological issues including depression, obsessive compulsive disorder, anxiety, stress, panic disorder, mood disorders, sleep disorders, and psychological distress appeared to associated with pregnant women (Sharma, Singh, Tempe, \& Malhotra, 2017). In particular, recent reviews reported that prevalence of depression (Woody, Ferrari, Siskind, Whiteford, \& Harris, 2017) or disorders relating posttraumatic stress (Yildiz, Ayers, \& Phillips, 2017) was $11.9 \%$ and $3.3 \%$ among pregnant women, respectively. In addition, pregnancy related physical health disorders including sleep disorders, back pain, fatigue, lack of energy, and reduced quality of life were also reported in this population (Olsson \& Lena, 2004). Leaving these issues unaddressed could be problematic that have associations with wide range of negative outcomes. For example, psychological disorders (i.e., depression, anxiety, mood disorders) were appeared to be related with variety of preterm labor, obstetric complications, pregnancy symptoms, as well as various negative neonatal and fetal consequences (Alder, Fink, Bitzer, Hösli, \& Holzgreve, 2007). A meta-analytical study showed that psychosocial stress was linked with increased risk of negative perinatal and neonatal outcomes (Littleton, Bye, Buck, \& Amacker, 2010). Other studies found negative effects of sleep disorders (Chang, Pien, Duntley, \& Macones, 2010), fatigue, pain, edema(Reynolds, 2003), and excessive maternal weight gain(Siega-Riz et al., 2009) on maternal and fetal outcomes. Taking together, these findings likely to suggest that addressing pregnancy related negative outcomes are critically essential for better health perspective for pregnant women.

Due to serious concern for maternal and fetal health, professional in health care area have been focusing on interventions that contribute to reduce and/or treat pregnancy related physical as well as psychological issues among pregnant women. Many researchers have been interesting on exercise based interventions for addressing pregnancy related issues in pregnant women (Chan, Au Yeung, \& Law, 2019). Aquatic exercises have been considering a form of exercise programs those are planned and developed to perform in water or swimming pools. This type of intervention have been using for therapeutic purpose for many years in health care setting. Regular involvement in aquatic exercise programs has been associated with physical and psychological benefits for women. Aquatic exercise showed indications of reduction in depression, enhanced self-efficacy, improvements in quality of life and physical fitness in women (Lee, Chang, \& Ahn, 2007). It appeared to exhibit positive effect on sleep(S. Delevatti et al., 2018), edema(Gianesini et al., 2016), fatigue(Cantarero-Villanueva et al., 2013), weight control(Kasprzak \& Pilaczyńska-Szcześniak, 2014), and pain(Munguía-Izquierdo \& Legaz-Arrese, 2007) among women. These findings lead us to conclude that aquatic exercise results in beneficial outcomes regarding physical and psychological well-being of the women.

To this end, it can be hypothesized that if women during pregnancy experience specific physical issues (i.e., pain, edema, fatigue, sleep, and weight gain) and negative psychological symptoms (i.e. depression, anxiety, and psychological distress) and aquatic exercise can potentially contribute to improve these conditions, then, it can be logically assumed that aquatic exercise may have the potential to deal with these pregnancy related outcomes. Aquatic exercise programs specifically considered among the most appropriate exercise intervention for pregnant women(Juhl, Kogevinas, Andersen, Andersen, \& Olsen, 2010). It has been suggested to be safe, joyful, offer moderate intensity workload and easy to perform during pregnancy (Backhausen et al., 2014; Juhl et al., 2010). In particular, exercising in water reduces $83 \%$ weight of pregnant women that results reducing weight bearing on lower extremities and thus reduces the risk of musculoskeletal injuries during exercise in pregnant women (Alberton et al., 2019). These findings likely to suggest that aquatic exercise programs seem more tailored in connection with conditions associated with pregnant women.

Above discussions lead us to conclude that aquatic exercises can be considered an important therapeutic intervention strategy to deal with variety of pregnancy related outcomes. Best health care practices require evidence based knowledge and evidence based policies for implementations. These approaches encourage clinicians and practitioners for systematic and critical evaluation of the effectiveness of the interventions before implementation. However, there is no review exists that critically assessed existing evidences showing beneficial effects of this intervention for these women. It seems important to present indepth and critical analysis concerning efficacy of aquatic exercise programs for reduction and/or treatment of some common physical and psychological conditions that women generally experience during pregnancy. Therefore, this review sought to present qualitative syntheses of the existing research on this topic. Another objective of this work was to identify gaps in existing work and suggest some ideas for future research in this area of research. This work may help professionals in health care setting to make decisions concerning implementing non-pharmacological treatment interventions while addressing pregnancy related issues during practice. Aquatic exercise was defined as all type of physical activities and exercise programs those were designed to perform in water.

\section{Methods}

\subsection{Search Strategy}

Published research articles were systematically searched in major research data bases including Science Direct, Taylor \& Francis, PubMed, Medline Plus, PsycINFO, ProQuest, Wiley Online Library, SAGE Journals, and Springer Link in August 2019. Search strategy consisted of using combination of aquatic exercise related keywords (i.e., aquatic exercise, exercise in water, swimming, water based exercise) along with pregnancy related keywords (i.e., pregnancy, pregnant women, maternal, gestation, antenatal, and prenatal). 


\subsection{Inclusion and Exclusion Criteria}

Eligibility criteria for inclusion were as follow: 1) studies presented data involving aquatic exercise programs effects on pregnancy related physical or psychological outcomes, 2) studies used any research designs including randomized control trials, clinical control trials, cohort, time series designs, case studies, longitudinal designs, qualitative, and cross-sectional designs, 3) studies selected health or patients pregnant women of any age, 4) published in peer review journals in English language, and 5) published in any geographical region or any country. Studies were excluded that met following criteria: 1) unpublished studies, 2) thesis and dissertations, 3) published in languages other than English, and 4) did not exists data related to variables included in this review.

\subsection{Data Extraction}

According to set criteria, the studies involving titles and abstracts were retrieved and thoroughly screened for relevancy. A second expert again screened the selected articles and only those articles were finally selected that were verified by second expert. Full texts were obtained and in depth and careful screening was carried out based on eligibility criteria set for this review. Data concerning authors, publishing year, country, sample characteristics, study designs, interventions and exercise measures, outcomes measures, data analysis, and results and findings were extracted (see table 1). A systematic review thought to be appropriate due to diverse nature of samples, interventional procedures, study designs, data analysis procedures.

\subsection{Quality Appraisal}

To evaluate the quality of each selected study, we used "The Quality Assessment Tool for Quantitative Studies" that has been widely employed for assessing study quality in health care (Chan et al., 2019; Project, 1998). The admissible studies were ranked as weak, moderate or strong based on assessment guide and dictionary for this tool on six point criteria including i) selection bias, ii) study design, iii) data collection, iv) confounders, v) rater blinding, and vi) withdrawals. In accordance with guidelines, studies having no weak rating on any of the six categories were rated as strong on overall rating. The studies had one weak rating were considered having moderate methodological quality study. All studies that had more than one weak rating on six point categories were rated as weak methodological quality studies.

\section{Results}

\subsection{Search Results}

As a result undertaking systematic search for related studies, a total 1989 records were appeared. Full search results are presented in Figure 1. After removing the duplicates, 1227 studies left that were selected for carrying out screening process for eligibility. Studies that did not meet inclusion and exclusion criteria set for this review were excluded. This resulted in 17 articles that were finally selected to include in this review.
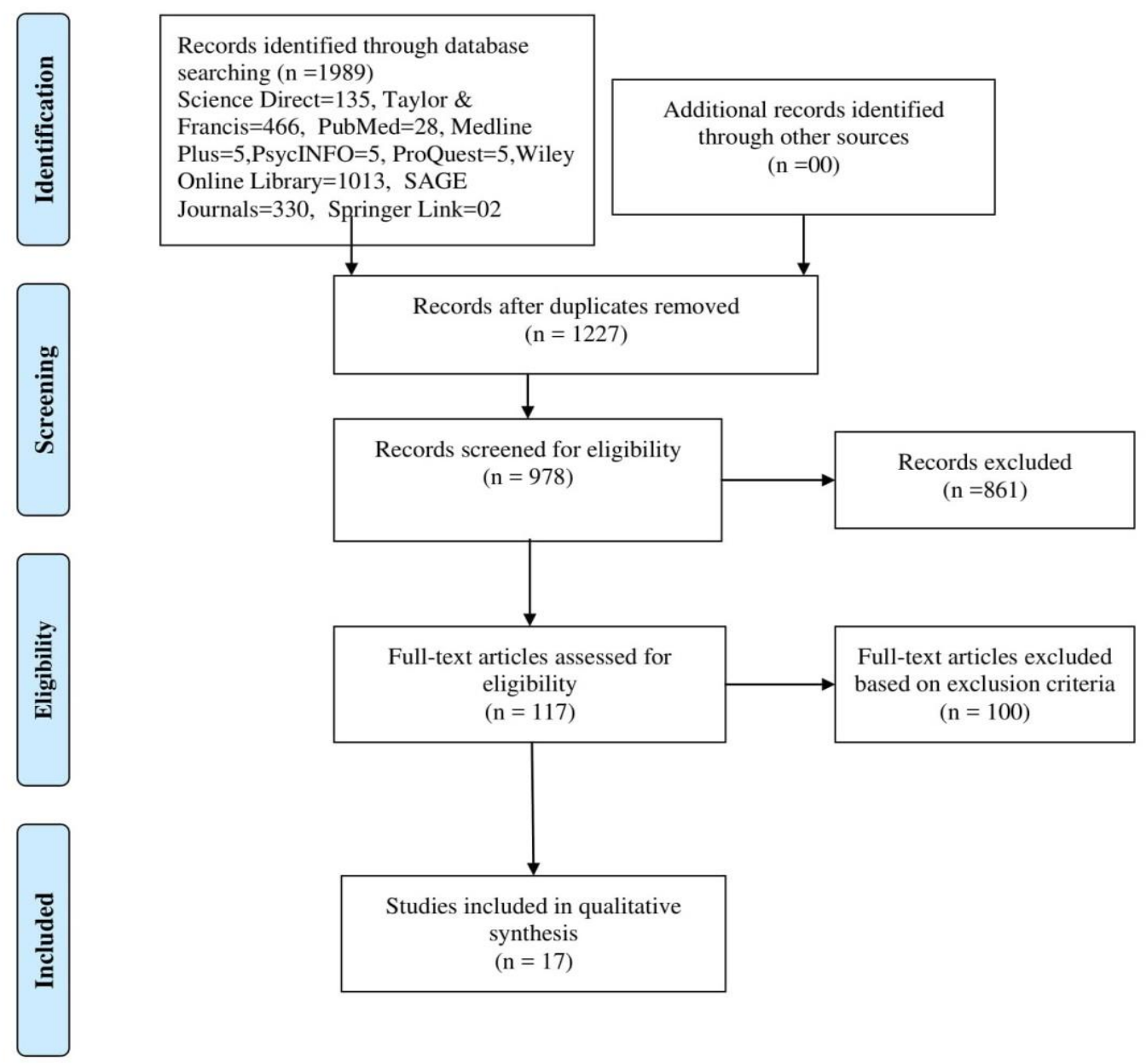
Figure 1. PRISMA flow chart showing procedure for litrature search and selection of studies assessed effects of aquatic exercise on

\subsection{Quality of the Included Studies}

pregnancy related outcomes

Among 17 included studies, $3(17.64 \%)$ were rated as strong and $14(82.35 \%)$ as moderate with respect to their methodological quality (see table 1). This shows the quality of studies done in this specific area.

Table 1 Quality appraisal of the included studies assessing aquatic exercise effects on pregnancy issues.

\begin{tabular}{|c|c|c|c|c|c|c|c|c|}
\hline Sr.\# & $\begin{array}{l}\text { Study/ } \\
\text { Design }\end{array}$ & $\begin{array}{c}\text { A } \\
\text { Bias in } \\
\text { Selection }\end{array}$ & $\begin{array}{c}\text { B } \\
\text { Study } \\
\text { Design }\end{array}$ & $\begin{array}{c}\text { C } \\
\text { Confounders }\end{array}$ & $\begin{array}{c}\text { D } \\
\text { Rater } \\
\text { Blinding }\end{array}$ & $\begin{array}{c}\mathrm{E} \\
\text { Data } \\
\text { Collection }\end{array}$ & $\begin{array}{c}\mathrm{F} \\
\text { Withdrawal }\end{array}$ & $\begin{array}{l}\text { Overall } \\
\text { Rating }\end{array}$ \\
\hline 1 & $\begin{array}{l}\text { Backhaus, et } \\
\text { al., (2017) }\end{array}$ & S & $\mathrm{S}$ & S & M & S & S & strong \\
\hline 2 & $\begin{array}{c}\text { Bacchi, et al., } \\
\text { (2017 }\end{array}$ & $\mathrm{S}$ & S & S & M & $S$ & M & strong \\
\hline 3 & $\begin{array}{l}\text { Cavalcante, et } \\
\text { al., (2009) }\end{array}$ & M & $\mathrm{S}$ & M & M & $\mathrm{S}$ & M & strong \\
\hline 4 & $\begin{array}{c}\text { Lox et al., } \\
(2000) \\
\text { Interrupted } \\
\text { time series }\end{array}$ & M & M & M & W & $\mathrm{S}$ & $\mathrm{S}$ & moderate \\
\hline 5 & $\begin{array}{c}\text { Parker, et al., } \\
2003 . \\
\text { Cohort }\end{array}$ & M & M & M & W & $\mathrm{S}$ & S & moderate \\
\hline 6 & $\begin{array}{c}\text { Granath, et al., } \\
\text { (2006) } \\
\text { CCT }\end{array}$ & S & S & M & W & $\mathrm{S}$ & S & moderate \\
\hline 7 & $\begin{array}{c}\text { Polman, et al., } \\
(2007)\end{array}$ & M & M & M & W & $\mathrm{S}$ & $S$ & moderate \\
\hline 8 & $\begin{array}{c}\text { Kihlstrand, et } \\
\text { al., (1999) } \\
\text { CCT }\end{array}$ & M & S & S & W & $\mathrm{S}$ & M & moderate \\
\hline 9 & $\begin{array}{c}\text { Cordero, et al., } \\
\text { (2018) }\end{array}$ & $\mathrm{S}$ & S & $\mathrm{S}$ & W & $\mathrm{S}$ & $\mathrm{S}$ & moderate \\
\hline 10 & $\begin{array}{c}\text { Scott \& } \\
\text { Hellawell, } \\
\text { (2018) }\end{array}$ & M & S & M & W & $\mathrm{S}$ & $S$ & moderate \\
\hline 11 & $\begin{array}{c}\text { Baciuk, et al., } \\
(2008\end{array}$ & S & $S$ & S & W & $\mathrm{S}$ & $\mathrm{S}$ & moderate \\
\hline 12 & $\begin{array}{c}\text { Backhausen, et } \\
\text { al., (2014) }\end{array}$ & M & M & M & W & $\mathrm{S}$ & M & moderate \\
\hline 13 & $\begin{array}{l}\text { Vallim, et al., } \\
(2011)\end{array}$ & M & S & S & W & M & M & moderate \\
\hline 14 & $\begin{array}{c}\text { Smith \& } \\
\text { Michel, (2006) }\end{array}$ & M & $S$ & M & W & $\mathrm{S}$ & $S$ & moderate \\
\hline 15 & $\begin{array}{c}\text { Blanquea, et } \\
\text { al., (2017) }\end{array}$ & M & M & M & W & $S$ & $\mathrm{~S}$ & moderate \\
\hline 16 & $\begin{array}{c}\text { Juhl, et. al., } \\
(2010)\end{array}$ & S & $\mathrm{W}$ & M & M & $S$ & S & moderate \\
\hline 17 & $\begin{array}{l}\text { Hartmann, et } \\
\text { al., (2005) }\end{array}$ & W & M & M & M & $\mathrm{S}$ & $S$ & moderate \\
\hline
\end{tabular}




\subsection{Study Characteristics}

Table 2 Characteristics of the included studies assessing aquatic exercise effects on pregnancy and overall health.

\begin{tabular}{|c|c|c|c|c|c|c|}
\hline $\begin{array}{l}\text { Scott \& } \\
\text { Hellawell, } \\
(2018)\end{array}$ & $\begin{array}{l}23 \text { pregnant } \\
\text { women } \\
\text { with } \text { PGP } \\
\text { Age range = } \\
22-37 \text { yrs. } \\
\text { Mean }=31.9 \pm \\
3.95 \text { yrs. }\end{array}$ & RCT & $\begin{array}{l}\text { Aquatic exercise of } \\
\text { moderate intensity } \\
\text { (4 sessions/week) }\end{array}$ & $\begin{array}{l}\text { PGPQ, VAS, } \\
\text { PSFS, ASLR, } \\
\text { SEES }\end{array}$ & $\begin{array}{l}\text { Independent } \\
\text { Student's t-test } \\
\text { Box-and- } \\
\text { Whisker plot, } \\
\text { Shapiro-Wilk } \\
\text { test } \\
\text {. }\end{array}$ & $\begin{array}{l}\text { Group comparison results } \\
\text { (water-based vs. land-based) } \\
\text { showed the significant } \\
\text { difference for the positive well- } \\
\text { being }(p=0.000) \text {, the ASLR ( } p \\
=0.036) \text {, and fatigue subscales } \\
\text { of the SEES }(p=0.011) \text {. } \\
\text { Aquatic exercise during } \\
\text { pregnancy was considered more } \\
\text { beneficial to reduce fatigue, } \\
\text { foster well-being, and improve } \\
\text { ASLR scores in comparison } \\
\text { with land based exercise. }\end{array}$ \\
\hline $\begin{array}{l}\text { Vallim, et al., } \\
\text { (2011) }\end{array}$ & $\begin{array}{l}35 \text { pregnant } \\
\text { women ( } 26 \text { vs. } \\
24 \text { yrs.) }\end{array}$ & RCT & $\begin{array}{l}\text { Water aerobics } \\
\text { classes for } 50 \text { min } \\
3 \text { times/week }\end{array}$ & $\begin{array}{l}\text { Self-Developed } \\
\text { Questionnaire } \\
\text { WHOQOL-BREF, }\end{array}$ & $\begin{array}{l}\text { MANOVA } \\
\text { Water }\end{array}$ & $\begin{array}{l}\text { At the time of admission, } 71 \% \\
\text { pregnant women who were } \\
\text { practicing water aerobics } \\
\text { expected improvements in } \\
\text { physical well-being through } \\
\text { exercise. } \\
\text { At the end of the study, } 65 \% \\
\text { women believed that water } \\
\text { aerobics classes would make } \\
\text { childbirth easier for them. }\end{array}$ \\
\hline $\begin{array}{l}\text { Juhl, et al., } \\
(2010)\end{array}$ & $\begin{array}{l}48,781 \\
\text { pregnant } \\
\text { women }\end{array}$ & $\begin{array}{l}\text { Nationwide } \\
\text { Population-Based } \\
\text { Cohort }\end{array}$ & $\begin{array}{l}\text { Self-reports, } \\
\text { interview (yes/no) }\end{array}$ & $\begin{array}{l}\text { Ponderal index } \\
\text { Gestational age } \\
\text { (days, weight, and } \\
\text { length) }\end{array}$ & $\begin{array}{l}\text { Cox, linear and } \\
\text { logistic } \\
\text { regression. }\end{array}$ & $\begin{array}{l}\text { Risk of giving preterm birth } \\
\text { slightly reduced in women who } \\
\text { participated in swimming during } \\
\text { pregnancy }(R=0.80,95 \% \text { CI: } \\
0.72-0.88) \text { or the ratio of } \\
\text { congenital malformations with } \\
\text { childbirth minimized ( } R=0.89 \text {, } \\
\text { CI: } 0.80-0.98) \text {. } \\
\text { Aquatic exercise had positive } \\
\text { effects in birth related outcomes. }\end{array}$ \\
\hline $\begin{array}{l}\text { Smith \& } \\
\text { Michel, } \\
\text { (2006) }\end{array}$ & $\begin{array}{l}40 \text { pregnant } \\
\text { women } \\
\text { (gestation= } 19 \\
\text { weeks) }\end{array}$ & $\begin{array}{l}\text { Quasi- } \\
\text { experimental, } \\
\text { CCT }\end{array}$ & $\begin{array}{l}\text { Six-week } \\
\text { aquatic exercise } \\
\text { ( } 3 \text { sessions of } 60 \\
\text { min/week). }\end{array}$ & $\begin{array}{l}\text { PBSQ, } \\
\text { HPLP, SPDII. }\end{array}$ & $\begin{array}{l}\text { ANCOVA, } \\
\text { Independent t- } \\
\text { tests }\end{array}$ & $\begin{array}{l}\text { Health-promoting behaviors and } \\
\text { less physical discomfort were } \\
\text { noted in pregnant women who } \\
\text { took part in aquatic exercise } \\
\text { compared to non-exercisers. } \\
\text { Posttest scores showed women's } \\
\text { likeliness towards physical } \\
\text { exercise }(p=.006) \text {, stress } \\
\text { management }(p=.001) \text {, and } \\
\text { health-promoting behaviors ( } p= \\
.05) \text { among exercising women. }\end{array}$ \\
\hline $\begin{array}{l}\text { Cavalcante, et } \\
\text { al., (2009) }\end{array}$ & $\begin{array}{l}71 \text { pregnant } \\
\text { women }\end{array}$ & RCT & $\begin{array}{l}\text { Fifty-min moderate } \\
\text { water aerobics } \\
\text { exercise (3-times a } \\
\text { week). }\end{array}$ & $\begin{array}{l}\text { Education level, } \\
\text { gestational age, } \\
\text { abortions or } \\
\text { cesarean sections } \\
\text { undergone } \\
\text { previously }\end{array}$ & $\begin{array}{l}\text { MANOVA, } \\
\text { Chi-square, } \\
\text { Student's t-tests }\end{array}$ & $\begin{array}{l}\text { Type of delivery, preterm birth } \\
\text { rate, alteration in maternal body } \\
\text { composition, neonatal weight or } \\
\text { well-being was not associated } \\
\text { with water aerobics. } \\
\text { Water aerobics proved to be safe } \\
\text { and may be considered } \\
\text { beneficial for indirect outcomes } \\
\text { e.g., the greater percentage } \\
\text { (around } 10 \% \text { ) of vaginal } \\
\text { deliveries. }\end{array}$ \\
\hline
\end{tabular}




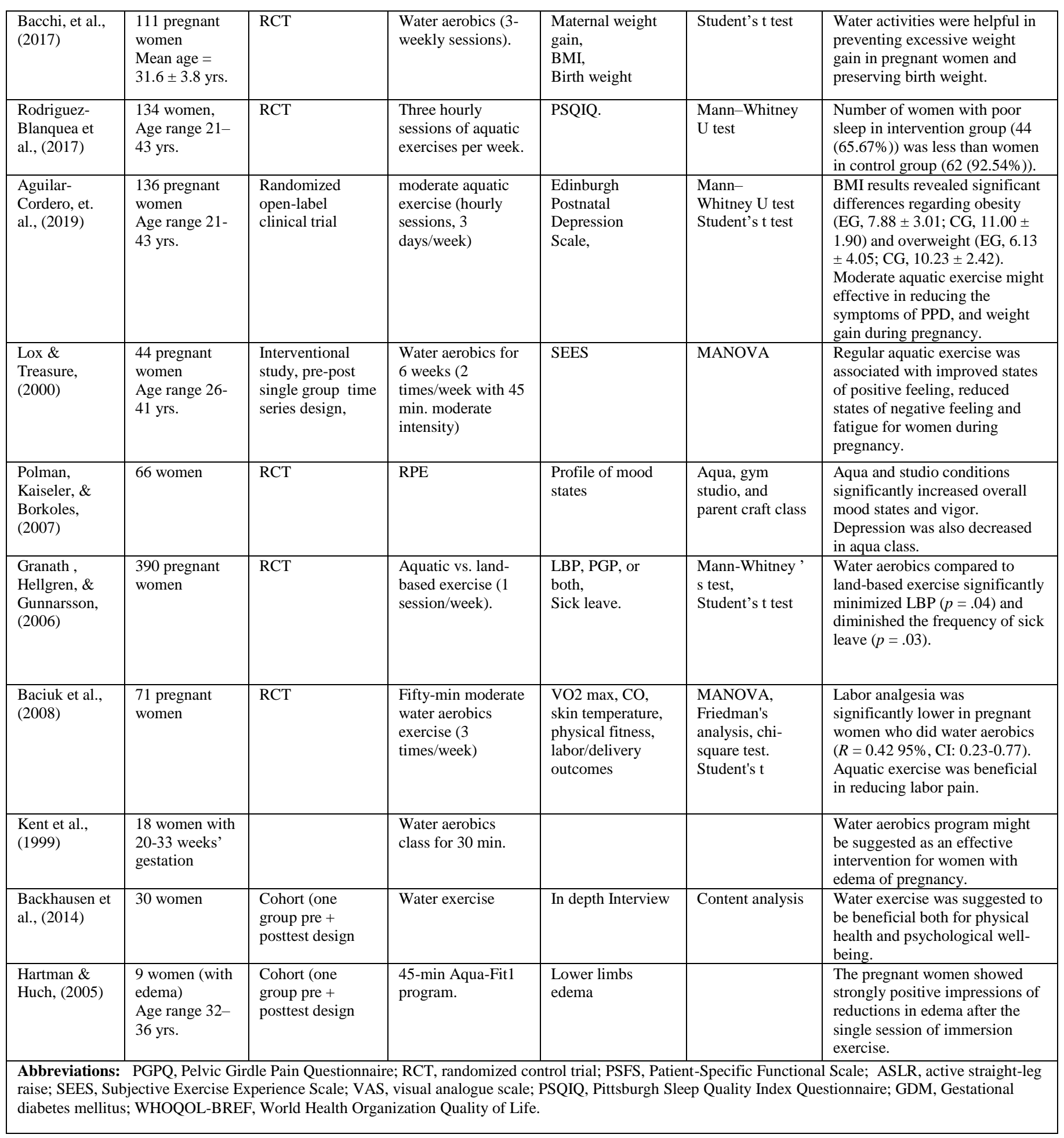




\subsubsection{Aquatic Exercise Effects on Physical Discomfort (Fatigue, Edema, or Pain)}

Ten of the selected articles presented data on the associations of aquatic exercise with physical discomfort. In general, ten studies included in this review consistently showed significantly positive effect of aquatic exercise on reduction in physical discomfort (Baciuk, Pereira, Cecatti, Braga, \& Cavalcante, 2008; Backhausen et al., 2014; Backhausen et al., 2017; Granath, Hellgren, \& Gunnarsson, 2006; Kent, Gregor, Deardorff, \& Katz, 1999; Kihlstrand, Stenman, Nilsson, \& Axelsson, 1999; Lox \& Treasure, 2000; Scott \& Hellawell, 2018; Smith \& Michel, 2006). For instance, these studies demonstrated beneficial effects of aquatic exercise for back pain (Backhausen et al., 2014; Backhausen et al., 2017; Granath et al., 2006; Kihlstrand et al., 1999), maternal discomfort (Smith \& Michel, 2006), pelvic pain (Scott \& Hellawell, 2018), fatigue (Backhausen et al., 2014; Lox \& Treasure, 2000; Scott \& Hellawell, 2018), labor pain (Baciuk et al., 2008), and edema related discomfort (Hartmann \& Huch, 2005; Kent et al., 1999). There was no study that reported adverse effects of aquatic exercise on the above-mentioned variables. In sum, these findings collectively suggest that aquatic exercise interventions can potentially reduce physical discomfort in pregnant women. However, more studies seem essential to increase strength of the evidence in favor of these findings.

\subsubsection{Aquatic Exercise Effects on Psychological Health}

Seven of the included studies assessed aquatic exercise effects on psychological health and well-being. These studies indicated that aquatic exercises can potentially reduce stress (Parker \& Smith, 2003), decrease psychological distress(Scott \& Hellawell, 2018),improve stress management and body image(Smith \& Michel, 2006), decrease depression (Aguilar-Cordero, SánchezGarcía, Rodriguez-Blanque, Sánchez-López, \& Mur-Villar, 2019), foster positive feelings (Lox \& Treasure, 2000), improve mood and vigor, and decrease depression (Polman, Kaiseler, \& Borkoles, 2007), and enhance pleasant feelings and decrease anxiety (Backhausen et al., 2014). In general, these data from these studies provided support for effectiveness of exercises in aquatic environment for reducing negative psychological conditions and enhancing positive psychological outcomes in pregnant women. No study showed negative outcome of aquatic exercises interventions on psychological health of the pregnant women. This highlights that there is some possibility to prescribe exercises intervention in aquatic environment for pregnant women with experiencing negative feelings, anxiety and depression related symptoms.

\subsubsection{Aquatic Exercise Effects on Quality of Life}

Of the selected studies, there was only one study that investigated the effects of aquatic exercise on 'quality of life' among pregnant women. In this regard, Vallim, A.L., et al., (Vallim et al., 2011) conducted a study involving 35 women in water exercise condition in which intervention group underwent three classes of aquatic aerobic exercises per week whereas control group received normal hath care. The analysis yielded no significant difference on the quality of life measure between both groups. This suggests that there is no relationship between aquatic aerobics and quality of life among inactive women with pregnancy. No final conclusion can be drawn based on insufficient data available from only one study.

\subsubsection{Aquatic Exercise Effects on Sleep}

We found only two studies that presented data regarding relationship between aquatic exercises and sleep in pregnant women. Both studies reported a significantly positive effect of aquatic exercise on sleep (Backhausen et al., 2014; Rodriguez-Blanque, Sánchez-García, Sánchez-López, Mur-Villar, \& Aguilar-Cordero, 2018). Findings from these two studies appeared to favor the idea of utilizing aquatic exercises as an effective mean to improve sleep among pregnant women. However, the existing data is insufficient that hinders drawing definite conclusion regarding effectiveness of this intervention for improving sleep in pregnant women.

\subsubsection{Aquatic Exercise Effects on Maternal Weight Control}

We found the data regarding association between aquatic exercise and maternal weight control only in four studies selected for this analysis (Aguilar-Cordero et al., 2019; Bacchi, Mottola, Perales, Refoyo, \& Barakat, 2018; Backhausen et al., 2014; Vallim et al., 2011). Studies included in this section consistently demonstrated positive impact of involvement in aquatic exercise programs on controlling excessive maternal weight among the samples of pregnant women. These findings highlight the efficacy of aquatic exercise programs for excessive weight control during pregnancy. However, with only four studies provided support for the effectiveness of this intervention for controlling excessive weight gain among these individuals remains unconfirmed unless availability of more data from further studies on this domain.

\section{Discussion}

Pregnant women, in many cases, appeared to experience wide range problems concerning physical discomfort (edema, pain, fatigue), and psychological issues (anxiety, stress, depression, disturbed mood). Women also reported to exhibit problems in sleep and excessive weight gain during pregnancy. In this connection, effective interventions required to develop for the purpose of improving these conditions that further could enhance quality of life in these individuals. Past research has demonstrated that aquatic exercise programs appeared to be particularly beneficial to boost physical and psychological wellbeing. It can be hypothetically assumed that exercise programs in an aquatic environment particularly tailored with the needs and interests of pregnant women would be more effective to deal pregnancy related physical and psychological issues. This work serves to present qualitative synthesis of evidence based on published research assessing efficacy of water based exercise interventions on the alleviation and/or enhancement of wide range physical and psychological pregnancy related outcomes. 
One main finding emerged from this data is effectiveness of aquatic exercise programs on improvement in various symptoms of physical discomfort in pregnant women. This finding found to be consistent in demonstrating such effect across all of the included studies. None of the studies presented adverse outcomes of the intervention on the any of the physical discomfort variables. In addition, there were no conflicting results reported in any of the included study. In this regard, aquatic exercise appeared to be beneficial for improvements in back pain, maternal discomfort, pelvic pain, fatigue, labor pain and edema related pain. More data from future research would add strength of the evidence for the effectiveness of this intervention. Another main findings emerged from this data is positive effect of aquatic exercise on improving level of variety of psychological variables in pregnant women. This effect appeared to be consistent across all of the included studies in this review. The positive effects were emerged for variety of the psychological outcomes including stress, psychological distress, body image, positive feelings, mood, vigor, depression, and anxiety. These findings likely to suggest that aquatic exercise programs can be used to as an effective interventional strategy to improve physical pain, to enhance positive psychological outcomes and to treat negative psychological symptoms (i.e. anxiety, depression, stress, negative body image) in pregnant women. This could potentially contribute to physical and psychological well-being of this population.

Furthermore, we found evidence from four included studies exhibiting beneficial effects of aquatic exercise for excessive maternal weight gain. All of the four studies demonstrated consistent positive effects for controlling weight in pregnant women. Although this data is promising with respect to such effect on pregnancy related weight gain, however, this data seems inadequate that hinders drawing of definite conclusion. This indeed fosters the idea of conducting further studies that would help to reach final conclusion. This review found no evidence for beneficial effects of aquatic exercise for the measures of quality of life. However, we found little support from two studies for positive effects of aquatic exercise for pregnancy related sleep problems. Based on insufficient data obtained from two studies in favor of beneficial effects of aquatic exercise for sleep related issues, we are not confident to suggest this intervention to address sleep related issues in these individuals.

In sum, based on above discussion, it can be concluded that aquatic excise may be suggested as an intervention to address issues concerning physical discomfort, psychological symptoms, and managing maternal weight in pregnancy. In addition, this review study found no effect of aquatic exercise on measures of quality of life or insufficient support for sleep related problems in the samples of pregnant women. However, these findings needed to be verified with more studies addressing these issues.

\section{Limitations}

Studies in English language were included in this review that led to exclude studies published in other languages. This review focused only a few common physical and psychological outcomes including edema, fatigue, pain, sleep, quality of life, maternal weight gain and other psychological variables. This resulted in studies limited to the variables of our interest in this review. Future review should broaden the scope of the reviews to include birth related outcomes, newborn health, and pregnancy related defects regarding effectiveness of aquatic exercise programs for women with pregnancy.

\section{Practical Implications and Recommendations}

Existing evidence regarding positive effects of aquatic exercise on some pregnancy related outcomes likely to suggest that there is some possibility to use this intervention to reduce and/or treat some issues concerning physical discomfort, psychological health, and maternal weight management in the population of pregnant women. However, these implications should be interpreted with caution because these are based on a few published studies on this topic.

It is evident that exercise with various intensities, durations, and frequency have different impact on physical and psychological health. It has been suggesting that only the appropriate dose of exercise is essential for optimal health related benefits. The findings emerged from this review need to extend using aquatic exercise intervention with various intensities, duration, frequency, and different exercise dosages. It would be more interesting to investigate differences with respect to effects on pregnancy related outcomes comparing samples of professional swimmers versus non-swimmers. This paradigm would highlight the impact of long-term training versus short-term training on the pregnancy related variables. In particular, this view identified that studies with strong methodological quality are lacking. Insufficient or no data exists on the investigating effects of this intervention on sleep and quality of life. These issues need to be addressing in future research.

\section{References}

Aguilar-Cordero, M. J., Sánchez-García, J. C., Rodriguez-Blanque, R., Sánchez-López, A. M., \& Mur-Villar, N. (2019). Moderate physical activity in an aquatic environment during pregnancy (SWEP study) and its influence in preventing postpartum depression. Journal of the American Psychiatric Nurses Association, 25(2), 112-121.

Alberton, C. L., Bgeginski, R., Pinto, S. S., Nunes, G. N., Andrade, L. S., Brasil, B., \& Domingues, M. R. (2019). Water-based exercises in pregnancy: Apparent weight in immersion and ground reaction force at third trimester. Clinical Biomechanics, 67, 148-152. 
Alder, J., Fink, N., Bitzer, J., Hösli, I., \& Holzgreve, W. (2007). Depression and anxiety during pregnancy: A risk factor for obstetric, fetal and neonatal outcome? A critical review of the literature. The Journal of Maternal-Fetal \& Neonatal Medicine, 20(3), 189-209. doi:10.1080/14767050701209560

Bacchi, M., Mottola, M. F., Perales, M., Refoyo, I., \& Barakat, R. (2018). Aquatic activities during pregnancy prevent excessive maternal weight gain and preserve birth weight: A randomized clinical trial. American Journal of Health Promotion, 32(3), 729-735.

Baciuk, E. P., Pereira, R. I., Cecatti, J. G., Braga, A. F., \& Cavalcante, S. R. (2008). Water aerobics in pregnancy: cardiovascular response, labor and neonatal outcomes. Reproductive Health, 5(1), 10.

Backhausen, M. G., Katballe, M., Hansson, H., Tabor, A., Damm, P., \& Hegaard, H. K. (2014). A standardised individual unsupervised water exercise intervention for healthy pregnant women. A qualitative feasibility study. Sexual \& Reproductive Healthcare, 5(4), 176-181.

Backhausen, M. G., Tabor, A., Albert, H., Rosthøj, S., Damm, P., \& Hegaard, H. K. (2017). The effects of an unsupervised water exercise program on low back pain and sick leave among healthy pregnant women-A randomised controlled trial. PLoS ONE, 12(9), e0182114.

Cantarero-Villanueva, I., Fernández-Lao, C., Cuesta-Vargas, A. I., Del Moral-Avila, R., Fernández-de-las-Peñas, C., \& Arroyo-Morales, M. (2013). The effectiveness of a deep water aquatic exercise program in cancer-related fatigue in breast cancer survivors: a randomized controlled trial. Archives of Physical Medicine and Rehabilitation, 94(2), 221230.

Chan, C. W., Au Yeung, E., \& Law, B. M. (2019). Effectiveness of Physical Activity Interventions on Pregnancy-Related Outcomes among Pregnant Women: A Systematic Review. International Journal of Environmental Research and Public Health, 16(10), 1840.

Chang, J. J., Pien, G. W., Duntley, S. P., \& Macones, G. A. (2010). Sleep deprivation during pregnancy and maternal and fetal outcomes: is there a relationship? Sleep Medicine Reviews, 14(2), 107-114. doi:10.1016/j.smrv.2009.05.001

Gianesini, S., Tessari, M., Bacciglieri, P., Malagoni, A. M., Menegatti, E., Occhionorelli, S., . . . Zamboni, P. (2016). A specifically designed aquatic exercise protocol to reduce chronic lower limb edema. Phlebology, 32(9), 594-600. doi:10.1177/0268355516673539

Granath, A. B., Hellgren, M. S., \& Gunnarsson, R. K. (2006). Water aerobics reduces sick leave due to low back pain during pregnancy. Journal of Obstetric, Gynecologic \& Neonatal Nursing, 35(4), 465-471.

Hartmann, S., \& Huch, R. (2005). Response of pregnancy leg edema to a single immersion exercise session. Acta Obstetricia et Gynecologica Scandinavica, 84(12), 1150-1153.

Juhl, M., Kogevinas, M., Andersen, P. K., Andersen, A.-M. N., \& Olsen, J. (2010). Is swimming during pregnancy a safe exercise? Epidemiology, 253-258.

Kasprzak, Z., \& Pilaczyńska-Szcześniak, Ł. (2014). Effects of regular physical exercises in the water on the metabolic profile of women with abdominal obesity. Journal of Human Kinetics, 41(1), 71-79.

Kent, T., Gregor, J., Deardorff, L., \& Katz, V. (1999). Edema of pregnancy: a comparison of water aerobics and static immersion. Obstetrics \& Gynecology, 94(5), 726-729.

Kihlstrand, M., Stenman, B., Nilsson, S., \& Axelsson, O. (1999). Water-gymnastics reduced the intensity of back/low back pain in pregnant women. Acta Obstetricia et Gynecologica Scandinavica, 78(3), 180-185.

Lee, S. O., Chang, K. O., \& Ahn, S. H. (2007). Effect of aquatic exercise program on pain, fatigue, body composition, physical fitness and psychological variables in women with arthritis. Korean Journal of Women Health Nursing, $13(3), 165$.

Littleton, H. L., Bye, K., Buck, K., \& Amacker, A. (2010). Psychosocial stress during pregnancy and perinatal outcomes: a meta-analytic review. Journal of Psychosomatic Obstetrics \& Gynecology, 31(4), $219-228$. doi:10.3109/0167482x.2010.518776

Lox, C. L., \& Treasure, D. C. (2000). Changes in feeling states following aquatic exercise during pregnancy. Journal of Applied Social Psychology, 30(3), 518-527.

Munguía-Izquierdo, D., \& Legaz-Arrese, A. (2007). Exercise in warm water decreases pain and improves cognitive function in middle-aged women with fibromyalgia. Clinical \& Experimental Rheumatology, 25(6), 823.

Olsson, C., \& Lena, N.-W. (2004). Health-related quality of life and physical ability among pregnant women with and without back pain in late pregnancy. Acta Obstetricia et Gynecologica Scandinavica, 83(4), 351-357. doi:10.1080/j.00016349.2004.00384.X

Parker, K. M., \& Smith, S. A. (2003). Aquatic-aerobic exercise as a means of stress reduction during pregnancy. The Journal of Perinatal Education, 12(1), 6-17.

Polman, R., Kaiseler, M., \& Borkoles, E. (2007). Effect of a single bout of exercise on the mood of pregnant women.

Project, E. P. H. P. (1998). Quality Assessment Tool For Quantitative Studies. Retrieved from https://merst.ca/ephpp/

Reynolds, D. (2003). Severe Gestational Edema. Journal of Midwifery \& Women's Health, 48(2), 146-148. doi:10.1016/s15269523(02)00419-1

Rodriguez-Blanque, R., Sánchez-García, J., Sánchez-López, A., Mur-Villar, N., \& Aguilar-Cordero, M. (2018). The influence of physical activity in water on sleep quality in pregnant women: A randomised trial. Women and Birth, 31(1), e51e58.

S. Delevatti, R., Schuch, F. B., Kanitz, A. C., Alberton, C. L., Marson, E. C., Lisboa, S. C., . . Kruel, L. F. M. (2018). Quality of life and sleep quality are similarly improved after aquatic or dry-land aerobic training in patients with type 2 
diabetes: A randomized clinical trial. Journal of Science and Medicine in Sport, 21(5), 483-488. doi:https://doi.org/10.1016/j.jsams.2017.08.024

Scott, K., \& Hellawell, M. (2018). Effects of water and land based exercise programmes on women experiencing pregnancyrelated pelvic girdle pain: a randomized controlled feasibility study.

Sharma, P., Singh, N., Tempe, A., \& Malhotra, M. (2017). Psychiatric disorders during pregnancy and postpartum. Journal of Pregnancy and Child Health, 4(317), 2.

Siega-Riz, A. M., Viswanathan, M., Moos, M.-K., Deierlein, A., Mumford, S., Knaack, J., . . . Lohr, K. N. (2009). A systematic review of outcomes of maternal weight gain according to the Institute of Medicine recommendations: birthweight, fetal growth, and postpartum weight retention. American Journal of Obstetrics and Gynecology, 201(4), 339. e331-339. e314.

Smith, S. A., \& Michel, Y. (2006). A pilot study on the effects of aquatic exercises on discomforts of pregnancy. Journal of Obstetric, Gynecologic \& Neonatal Nursing, 35(3), 315-323.

Vallim, A. L., Osis, M. J., Cecatti, J. G., Baciuk, É. P., Silveira, C., \& Cavalcante, S. R. (2011). Water exercises and quality of life during pregnancy. Reproductive Health, 8(1), 14.

Woody, C. A., Ferrari, A. J., Siskind, D. J., Whiteford, H. A., \& Harris, M. G. (2017). A systematic review and metaregression of the prevalence and incidence of perinatal depression. Journal of Affective Disorders, 219, 86-92.

Yildiz, P. D., Ayers, S., \& Phillips, L. (2017). The prevalence of posttraumatic stress disorder in pregnancy and after birth: A systematic review and meta-analysis. Journal of Affective Disorders, 208, 634-645. 